\title{
Breast cancer screening in women with mental illness: comparative meta-analysis of mammography uptake
}

Alex J. Mitchell, Isabel Espirito Santo Pereira, Motahare Yadegarfar, Shingai Pepereke, Vongai Mugadza and Brendon Stubbs

\section{Background}

There is a higher mortality rate due to cancer in people with mental illness and previous work suggests suboptimal medical care in this population. It remains unclear if this extends to breast cancer population screening.

\section{Aims}

To conduct a systematic review and meta-analysis to establish if women with a mental health condition are less likely to receive mammography screening compared with those without mental ill health.

\section{Method}

Major electronic databases were searched from inception until February 2014. We calculated odds ratios (OR) with a random effects meta-analysis comparing mammography screening rates among women with and without a mental illness. Results were stratified according to primary diagnosis including any mental illness, mood disorders, depression, severe mental illness (SMI), distress and anxiety.

\section{Results}

We identified 24 publications reporting breast cancer screening practices in women with mental illness $(n=715705)$. An additional 5 studies investigating screening for those with distress $(n=21491)$ but no diagnosis of mental disorder were identified. The pooled meta-analysis showed significantly reduced rates of mammography screening in women with mental illness $(\mathrm{OR}=0.71,95 \% \mathrm{Cl} 0.66-0.77)$, mood disorders $(\mathrm{OR}=0.83,95 \% \mathrm{Cl} 0.76-0.90)$ and particularly $\mathrm{SMI}(\mathrm{OR}=0.54,95 \% \mathrm{Cl} 0.45-0.65)$. No disparity was evident among women with distress alone.

\section{Conclusions}

Rates of mammography screening are lower in women with mental illness, particularly women with SMI, and this is not explained by the presence of emotional distress. Disparities in medical care due to mental illness clearly extend into preventive population screening.

\section{Declaration of interest}

None.
Compared with the general population, people with mental illness have a significantly reduced life expectancy. ${ }^{1-4}$ Despite increased awareness of the importance of physical health in people with mental illness, this mortality gap appears to be widening., ${ }^{5,6}$ Research suggests that there is an increased prevalence of metabolic disease, cardiovascular disease, osteoporosis, cancer and respiratory disease associated with mental illness, ${ }^{2,3,7}$ and clearly this mandates rates of medical interventions and medical monitoring that are at least equal to those in the general population. Unfortunately, people with mental illness consistently receive suboptimal medical care. ${ }^{1,8-11}$ Recently a number of narrative reviews have established the existence of inequalities in the physical healthcare provision for people with mental illness who have cancer. ${ }^{5,11-13}$ This is concerning, since among the general population cancer is a leading cause of death worldwide, accounting for about 8 million deaths in 2012. ${ }^{14}$ Breast cancer is second only to lung cancer as the leading cause of cancer deaths for women. ${ }^{15}$ In response to the increased mortality observed in women with breast cancer, at least 27 countries have nationwide screening for the condition. ${ }^{16}$ For instance, the US Preventive Services Task Force has recommended biennial mammography for women aged 50-74 years, ${ }^{17}$ and in the UK women aged 50-70 years (extending to $47-73$ years by the end of 2016) are invited to attend breast screening every 3 years as part of the National Health Service (NHS) breast screening programme. ${ }^{18}$ An independent review by Cancer Research UK and the National Cancer Director investigated the benefits and risks of breast screening in October 2011 and concluded that the UK breast screening programme prevents 1300 cancer deaths per year, with approximately 16000 women diagnosed each year but with about 4000 false positives. ${ }^{19}$ It is estimated that about 500 screening applications are needed to prevent one breast cancer death. ${ }^{20}$ Within the general population meta-analyses have demonstrated that mortality from breast cancer is reduced by $15-20 \%$ among adults eligible to receive screening. ${ }^{21-23}$ However, such screening is not without controversy. For instance, the recently updated Cochrane review stated that although screening reduces mortality by $15 \%$ there is a risk of overtreatment of approximately $30 \%$ among women in the general population. ${ }^{24}$

Women with a past or present diagnosis of a mental illness appear to be less likely to receive mammography compared with the general population. ${ }^{9,11}$ This is despite the fact that cancer mortality is substantially increased among this population, ${ }^{5,25-27}$ with those diagnosed with severe mental illness (SMI) at particular risk. This has led some authors to suggest that there is a need for targeted early detection and improved cancer screening among women with mental illness. ${ }^{26,27}$ Although it is true that some studies, such as that by Ji et al, have found no increase or even a reduction in the prevalence of certain types of cancer in those with schizophrenia, ${ }^{28}$ breast cancer risk appears to be consistently increased. Recently two systematic reviews reported a disparity in breast cancer screening among women with mental illness, ${ }^{9,11}$ but neither conducted a meta-analysis to quantify this relationship. Given the aforementioned concerns, there is a need to establish quantitatively if in fact women with mental illness are less likely to receive mammography screening. Thus, the aim of our systematic review and meta-analysis was to establish whether women with a past or present diagnosis of mental illness were less likely to receive mammography than members of the general population. Within this review we stratified the results to establish if a discrepancy existed in mammography screening due to a diagnosis of mental illness, 
mood disorders, depression, severe mental illness or distress and anxiety.

\section{Method}

This systematic review was conducted in accordance with the Meta-analysis of Observational Studies in Epidemiology (MOOSE) guidelines and with reference to the Preferred Reporting Items for Systematic Reviews and Meta-analyses (PRISMA) statement, ${ }^{29,30}$ utilising a predetermined but unregistered protocol.

\section{Eligibility criteria}

Studies were eligible if they included women with a diagnosis of non-organic psychiatric disorder including SMI (e.g. schizophrenia, psychosis), mood disorders (depression, anxiety) according to recognised diagnostic criteria (DSM-IV or ICD-10), ${ }^{31,32}$ or other valid measure. We also included studies that reported mammography screening among women with distress but no defined mental illness. Studies were also required to be comparative studies reporting mammography screening for women with and without a mental illness.

We did not aim to analyse studies that reported mammography screening in women with delirium, dementia, learning disability, eating disorder or alcohol use disorder. In fact we found no such study except those involving learning disability, which we excluded. ${ }^{33}$ We did not place any language restriction upon eligible studies and if we encountered multiple publications from the same study, only the most recent paper or article with the largest sample with complete data was included. If we encountered studies that conducted mammography in a sample of women with and without a mental illness but did not report the data required for the meta-analysis, we contacted the authors up to three times to acquire the variables of interest.

\section{Literature search and appraisal}

Two authors (A.J.M., B.S.) independently conducted searches of Medline, PubMed and EMBASE electronic databases from inception until February 2014. We used the following keywords: mammogr ${ }^{\star}$ OR breast screen* OR breast cancer screen AND mental OR psychiatr* OR depression OR mood OR anxiety OR SMI OR schizophrenia OR psychosis OR psychotic. We also looked for similar studies using the symptom of distress rather than formal psychiatric disorder. The searches of major electronic databases were supplemented by full-text searches of Web of Knowledge, Scopus, Science Direct, Ingenta Select, Springer LINK and Wiley-Blackwell and hand-searching of all included articles. Finally, we conducted online hand searches of major psychiatric journals from 2000 up to February 2014, including the BMJ, British Journal of Psychiatry, Schizophrenia Research, Schizophrenia Bulletin, Psychological Medicine, Acta Psychiatrica Scandinavica, American Journal of Psychiatry, Archives of General Psychiatry, Canadian Journal of Psychiatry, Journal of Psychiatric Research, Psychiatric Services and The Psychiatrist, and contacted numerous international experts to ensure completeness of data acquisition. Two authors independently completed the Newcastle-Ottawa Scale (NOS) evaluation for all included articles (A.J.M., B.S.); the scale is a reliable and valid tool to assess the methodological quality of observational studies. ${ }^{34}$

\section{Data extraction}

Data were extracted by four authors (I.P., M.Y., S.P., V.M.) and independently validated by another (A.J.M.) using a predetermined form. The data extracted included study design, setting, participant characteristics (number, mean age, gender, type of mental illness and classification criteria used), control participant characteristics, details of mammography screening measures and results, including statistical procedures used and factors adjusted for.

\section{Statistical analysis}

From the available data we calculated odds ratios (OR) together with the 95\% confidence intervals and $r$ values from each study. For the purposes of pooling data if we encountered relative risks (hazard ratios) among individual studies these were converted into odds ratios with reference to the reported control event rate, an adaption of a method described elsewhere. ${ }^{35}$ We then used a random effects meta-analysis, pooling odds ratios comparing mammography screening in those with and without a mental illness. Wherever possible we attempted to account for potential confounders in the literature as reported within each study and stratified results into adjusted and unadjusted analyses. Confidence intervals were extracted from all studies or calculated from the data provided. Between-study heterogeneity was assessed using the $I^{2}$ statistic. $^{36}$ Heterogeneity was further reduced by stratifying analyses by type of mental illness, but we required a minimum of three studies to justify separate pooling of results. Owing to the anticipated heterogeneity, all analysis was conducted with the DerSimonian \& Laird random effects meta-analysis, ${ }^{37}$ using Statsdirect for Windows (www.statsdirect.com). To assess publication bias Egger's regression method and the Begg-Mazumdar test, with a $P$ value below 0.05 suggesting the presence of bias, were used. ${ }^{38,39}$ In addition a funnel plot was generated for each analysis, in which the study-specific effect estimates were displayed in relation to the standard error in order to assess the potential presence of publication bias. Finally we calculated estimates of missed screens, based on the relative risk and prevalence of mental disorder, ${ }^{40,41}$ and the likely excess mortality by using the number of screening applications needed to prevent one death.

\section{Results}

After the removal of duplicates the initial searches yielded 110 valid hits and following the application of the eligibility criteria, 24 publications were included. ${ }^{42-65}$ These consisted of 41 analyses involving 715705 women with a diagnosis of mental illness and 5 analyses involving 21491 women with broadly defined distress. At the full-text screening stage 86 articles were excluded (Fig. 1). Common reasons for exclusion were that the paper contained no relevant data, was not comparative or had no valid diagnosis of mental illness. The studies were all conducted in North America except for two. ${ }^{47,51}$ Over half of the included studies (13 of 24) enquired about mammography screening over a 2-year period. Details of the included studies and participants are presented in online Table DS1. The NOS scores were good overall, with a mean score of 6.5 (s.d. $=0.9$ ), and only one study was rated as poor quality ${ }^{45}$ The summary of the NOS score for each study is presented in online Table DS1.

\section{Mammography screening rates}

\section{Mental illness}

In total 41 separate analyses involving a combined 715705 women were available to investigate the influence of any mental illness upon mammography screening (Fig. 2(a)). The random effects meta-analysis yielded a pooled OR of 0.71 (95\% CI $0.66-0.77$, $P<0.0001$ ), establishing that women with mental illness were significantly less likely to receive mammography screening compared with members of the general population. The $I^{2}$ 


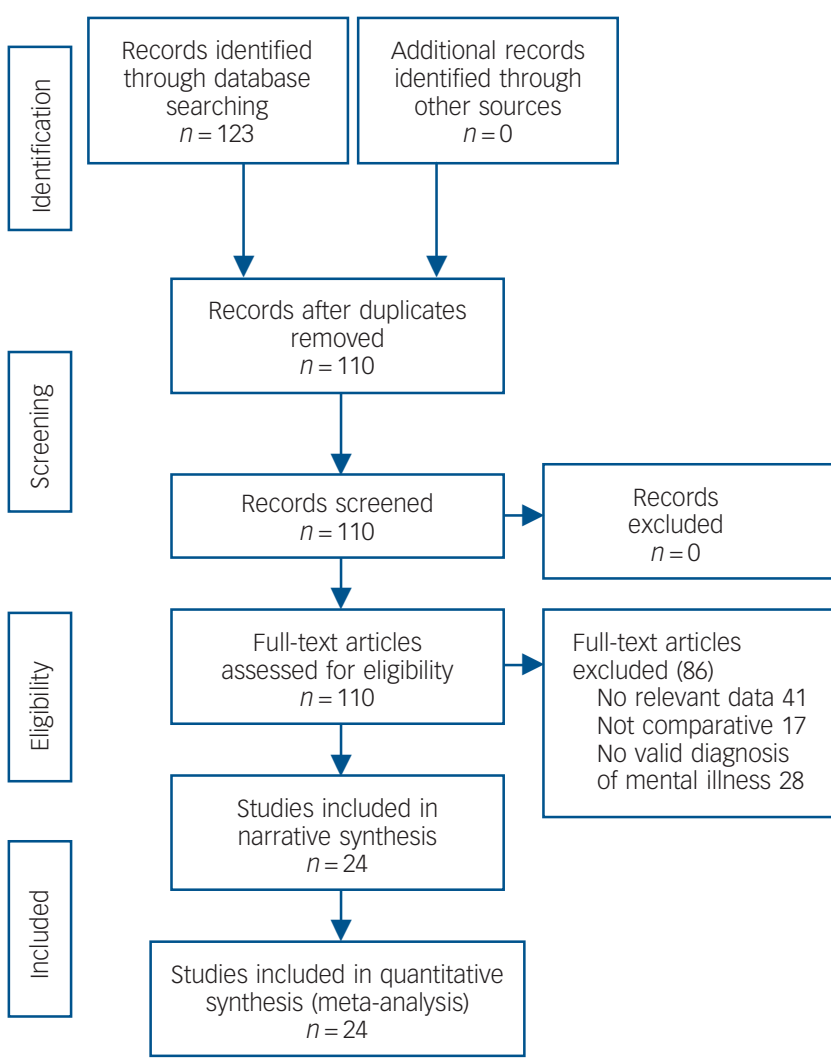

Fig. 1 Study search procedure.

statistic was high (95\%) indicating high heterogeneity. The funnel plot was symmetrical (Fig. 2(b)) and neither the Begg-Mazumdar (Kendall's ô $=-0.0585, P=0.58)$ nor the Egger bias $(-1.37$, $P=0.14)$ test demonstrated any evidence of publication bias.

\section{Mood disorders}

Next we pooled the results from 22 analyses reporting mammography screening rates in individuals with mood disorder and controls $(n=399153)$ (Fig. 3$)$. The pooled OR was 0.83 (95\% CI $0.76-0.90$, $P<0.0001$ ), establishing a significant reduction in mammography screening rates among women with mood disorders. However, although the $I^{2}$ statistic for the analysis was high (90\%), the funnel plot was symmetrical and the Begg-Mazumdar (Kendall's $\tau=-0.012, P=0.91)$ and Egger bias $(-0.357, P=0.69)$ tests did not demonstrate any evidence of publication bias. It was possible to pool the results of 17 analyses specifically investigating mammography screening rates in women with depression. This established an OR of 0.91 ( $95 \%$ CI $0.84-0.97, P=0.01$ ), indicating that women with depression are less likely to receive mammography screening compared with members of the general population. The $I^{2}$ was high (77\%), but inspection of the funnel plot and the Begg-Mazumdar (Kendall's $\tau=0, \quad P=0.96$ ) and Egger bias (0.765, $P=0.26)$ tests demonstrated there was no evidence of publication bias influencing the results.

\section{Serious mental illness}

We pooled eight separate analyses regarding mammography screening in women with SMI compared with general population controls $(n=387556)$ and found low heterogeneity $\left(I^{2}=43 \%\right.$; Fig. 4). The pooled OR was 0.54 (95\% CI $0.45-0.65)$ indicating that women with SMI are almost $50 \%$ less likely to receive mammography than members of the general population. The funnel plot was symmetrical and the Begg-Mazumdar test was satisfied (Kendall's $\tau=-0.5, P=0.06$ ), but Egger's test did indicate some evidence of publication bias $(-1.529, P=0.01)$.

\section{Distress}

In women with broadly defined distress but no formal diagnosis of mental illness we pooled five different analyses incorporating 21491 women. Results did not suggest that women with distress were significantly less likely to receive mammography screening compared with general population controls $(\mathrm{OR}=0.79,95 \% \mathrm{CI}$ 0.37-1.69, $P=0.54, I^{2}=88 \%$ ). The Begg-Mazumdar and Egger bias tests for both analyses demonstrated no evidence of publication bias.

\section{Missed screens}

Finally, we calculated estimates of missed screens based on the relative risk and prevalence of mental disorder and the likely excess mortality by using the number of screens needed to prevent one death (online Table DS2). This established that 45047 missed screening opportunities among women with mental illness might result in 90 deaths (95\% CI 67-111) in the UK annually. Excess mortality estimates for women with mood disorder and SMI were calculated at 16 (95\% CI 9-24) and 25 (95\% CI 17-34) from 7857 and 12571 missed screens respectively.

\section{Discussion}

To our knowledge this is the first meta-analysis investigating any general population medical screening according to diagnosis of mental illness and also the first regarding receipt of mammography. Results extend conclusions from previous narrative reviews showing disparities in medical care linked with mental illness. From qualifying mammography studies 715705 unique individuals were included and results consistently showed that women with mental illness were likely to receive suboptimal breast cancer screening compared with those without a mental illness. Specifically, there was a significantly reduced level of receipt of mammography screening in women with any mental illness as well as in women with mood disorders. Indeed, a subgroup analysis showed that there was also a significant low receipt in those with depression. However, the largest effect was seen in women with SMI, who had almost $50 \%$ lower odds of receiving mammography when indicated. Given an estimated population uptake of $77 . \%,{ }^{66}$ and 1.94 million mammograms per year in England, this represents a relative risk (RR) of 0.91 in those with any mental illness, or approximately 45000 missed screens, assuming a $27 \%$ prevalence of mental illness (online Table DS2). We also estimate an RR of 0.95 in mood disorders (or 7857 missed screens, assuming a $9 \%$ prevalence of mood disorder) and a RR of 0.84 in SMI (or approximately 12571 missed screens; assuming a 4\% prevalence of SMI). Given these figures, and the earlier calculation that about 500 screening applications may prevent one breast cancer death, then it is likely that this breast cancer screening inequality in women with mental ill health could result in 90 unnecessary deaths per year in the UK.

The results of our review might provide a partial explanation for the observation that cancer is detected later on average in people with mental illness, ${ }^{12,13,27}$ and also help account for the fact that a greater proportion of cancer with metastases at presentation is found in psychiatric patients. ${ }^{27}$ Coupled with the fact that people with a SMI such as schizophrenia are less likely to be offered timely treatment, ${ }^{13,27}$ it is possible that reduced 
Blackwell et al (2008) ${ }^{58}$ (Canada)

Green \& Pope $(2000)^{49}$

Druss et al (2008) ${ }^{48}$ (primary care)

Masterton et al (2010) ${ }^{54}$ (moderate)

Pirraglia et al (2004) $)^{52}$

Peytremann-Bridevaux et al (2008) $)^{51}$

Carney \& Jones (2006) ${ }^{42}$ (any low severity)

Carney \& Jones (2006) $)^{42}$ (mood disorder low severity)

Werneke et al (2006) ${ }^{46}$

Kempe et al (2013) ${ }^{59}$

Stecker et al (2007) $)^{53}$

Aggarwal et al $(2003)^{57}$

Pirraglia et al (2004) ${ }^{52}$

Masterton et al ((2010) $)^{54}$ (moderate)

Druss et al (2008) ${ }^{48}$

Druss et al (2008) $)^{48}$ (specialist)

Patten et al (2009) ${ }^{50}$

Blackwell et al (2008 ${ }^{58}$ (USA)

Druss et al (2002) $)^{44}$

Masterton et al (2010) ${ }^{54}$ (severe)

Vigod et al (2011)

Koroukian et al ((2012) ${ }^{65}$

Masterton et al (2010) ${ }^{54}$ (severe)

Chochinov et al (2009) ${ }^{43}$

Carney \& Jones (2006) ${ }^{42}$ (mood disorder medium severity)

Masterton et al (2010) ${ }^{54}$ (moderate)

Carney \& Jones (2006) ${ }^{42}$ (any medium severity)

Yee et al (2011)

lezzoni et al (2001) ${ }^{47}$

Masterton et al (2010) ${ }^{54}$ (severe)

Carney \& Jones (2006) ${ }^{42}$ (psychotic disorder low severity)

Carney \& Jones (2006) ${ }^{42}$ (psychotic disorder high severity)

Druss et al (2002)

Ludman et al $(2010)^{55}$

Carney \& Jones (2006) ${ }^{42}$ (psychotic disorder medium severity)

Werneke et al (2006) ${ }^{46}$

Carney \& Jones (2006) $)^{42}$

Lasser et al (2003) ${ }^{63}$

Carney \& Jones (2006) $)^{42}$ (mood disorder high severity)

Werneke et al (2006) ${ }^{46}$

Lindamer et al (2003)

Combined

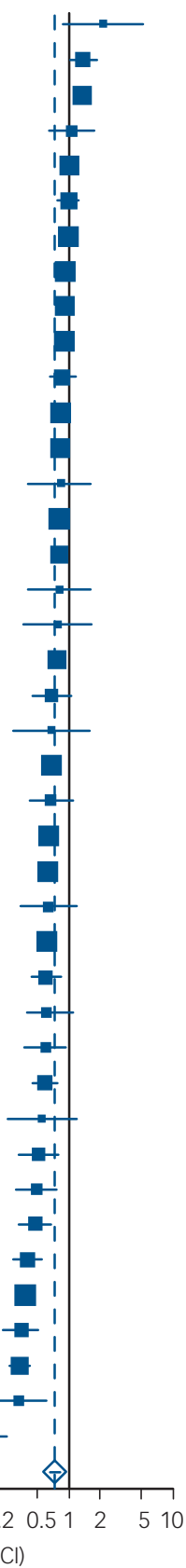

$2.14(0.88,5.20)$

$1.37(1.04,1.81)$

$1.35(1.16,1.61)$

$1.06(0.64,1.75)$

$1.01(0.86,1.18)$

$1.00(0.80,1.20)$

$0.98(0.95,1.01)$

$0.93(0.89,0.97)$

$0.91(0.80,1.04)$

$0.90(0.85,0.94)$

$0.87(0.66,1.13)$

$0.84(0.81,0.88)$

$0.84(0.73,0.97)$

$0.83(0.42,1.61)$

$0.82(0.79,0.85)$

$0.82(0.69,0.97)$

$0.80(0.40,1.60)$

$0.78(0.37,1.65)$

$0.78(0.67,0.91)$

$0.68(0.56,1.04)$

$0.68(0.29,1.59)$

$0.68(0.66,0.70)$

$0.67(0.42,1.07)$

$0.64(0.58,0.71)$

$0.63(0.57,0.69)$

$0.63(0.34,1.18)$

$0.62(0.59,0.66)$

$0.60(0.44,0.62)$

$0.60(0.40,1.10)$

$0.59(0.38,0.93)$

$0.59(0.45,0.78)$

$0.56(0.26,1.21)$

$0.52(0.34,0.79)$

$0.49(0.31,0.76)$

$0.47(0.33,0.67)$

$0.40(0.29,0.55)$

$0.38(0.33,0.43)$

$0.35(0.24,0.51)$

$0.34(0.28,0.42)$

$0.33(0.18,0.61)$

$0.40(0.00,0.25)$

$0.72(0.66,0.77)$

(b)

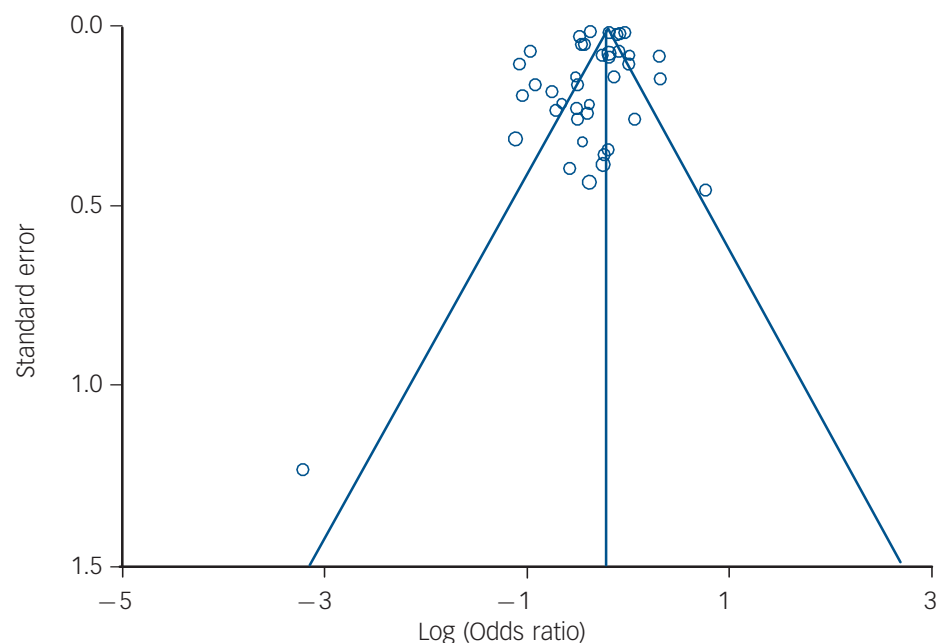

Fig. 2 Mammography screening in women with mental illness. (a) Pooled odds ratios: random effects meta-analysis. (b) Bias assessment plot. 


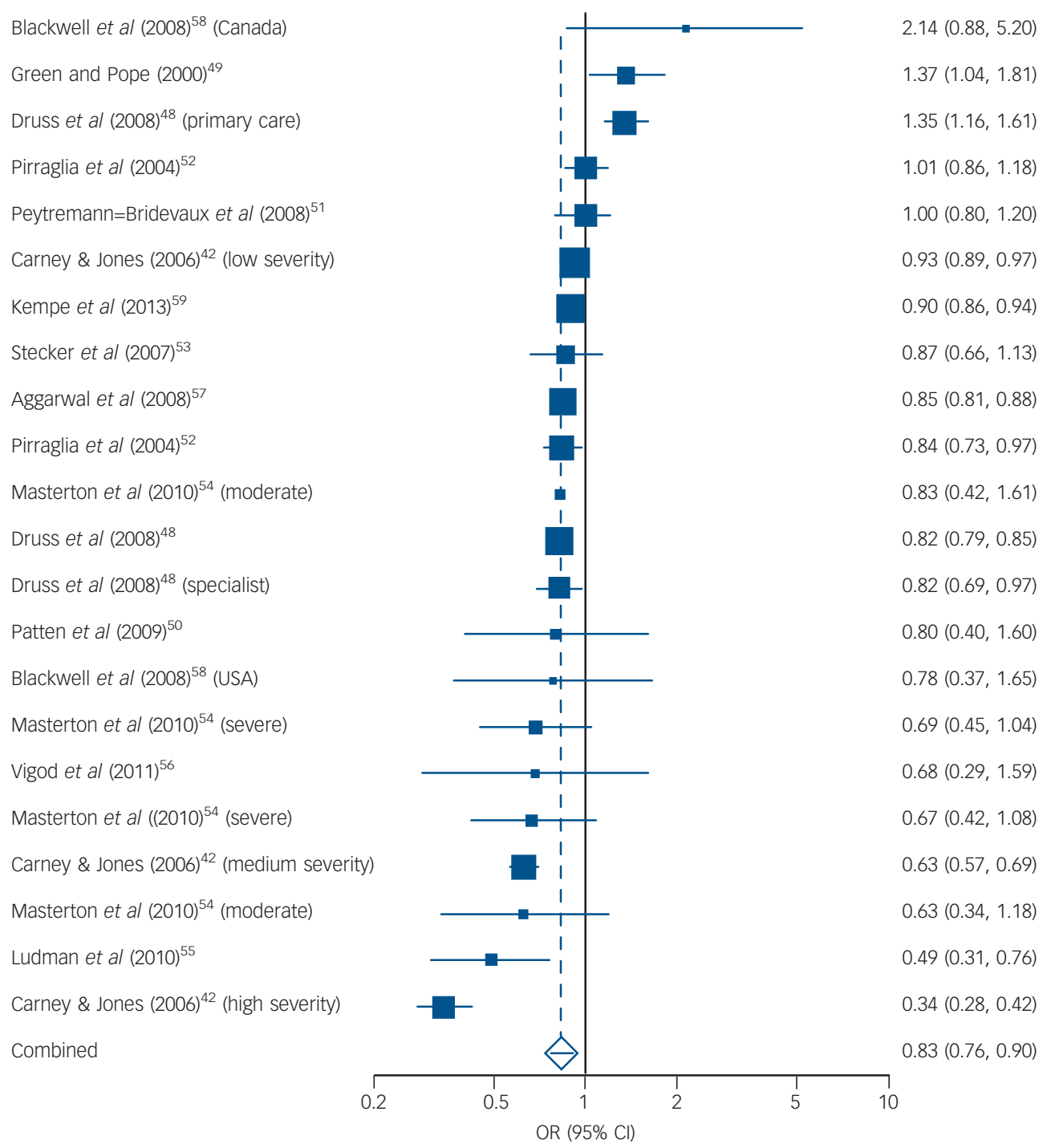

Fig. 3 Mammography screening in women with mood disorders. Pooled odds ratios: random effects meta-analysis.

mammography screening rates could explain why cancer-related mortality is higher among women with mental illness. ${ }^{67}$ However, at this stage these links are speculative and further research is warranted to establish more clearly if increasing mammography screening uptake among people with mental illness would improve patient outcomes. The results of our study are nevertheless consistent with the overall physical healthcare disparity seen in women with mental illness. ${ }^{67}$ For instance, Osborn et al and Roberts et al found that those with a diagnosis of schizophrenia were about half as likely as comparator groups to have had their blood pressure or smoking status recorded in primary care. ${ }^{68,69}$ Indeed, a recent nationwide survey of medical monitoring across the UK found lower receipt of medical testing in those with SMI compared with people with diabetes. ${ }^{70}$ Differences were still apparent once non-attendance was adjusted for. We have previously demonstrated that people with mental illness receive lower rates of medical care, lower rates of appropriate drug treatment and lower rates of medical procedures. ${ }^{8,9,71}$ Here we extend these findings to highlight a disparity in mass medical population-based screening for breast cancer.

\section{Possible reasons for low screening rates}

One plausible hypothesis is that the low uptake in those with mental illness is explained by current distress. Stress, distress and anxiety have been linked to short-term risk-averse behaviours resulting in avoidance of screening invitations. ${ }^{72}$ Indeed, distress has been linked with low uptake of mass screening such as mammography and colorectal cancer screening. ${ }^{73,74}$ However, there may also be a bimodal, inverted U-shaped relationship between screening and anxiety, with both high concern and high distress linked with lower screening rates. ${ }^{75}$ In this study in a large sample of 21491 women we found no significant link between distress and mammography. Unfortunately there were insufficient data to analyse the effect of anxiety alone, but when anxiety and distress were pooled we still were unable to demonstrate any consistent link. This suggests that current distress (or anxiety) is probably not the explanation for low receipt of mammography.

Another possible reason for the low screening rates among women with mental illness is low rates of presentation for medical help, largely a patient-determined factor (help-seeking). For instance, Hardy \& Gray found that only $66 \%$ of those with SMI attended an appointment in primary care when specifically invited for a physical health check, compared with $81 \%$ of those with diabetes in the same centre. ${ }^{76}$ However, other studies have found that attendance is not the main variable in determining medical care inequalities. ${ }^{8,9,70}$ Kahn et al stipulated that patient education is key to facilitating breast cancer screening among women with mental illness. ${ }^{77}$ For example, patients commonly fear pain or 


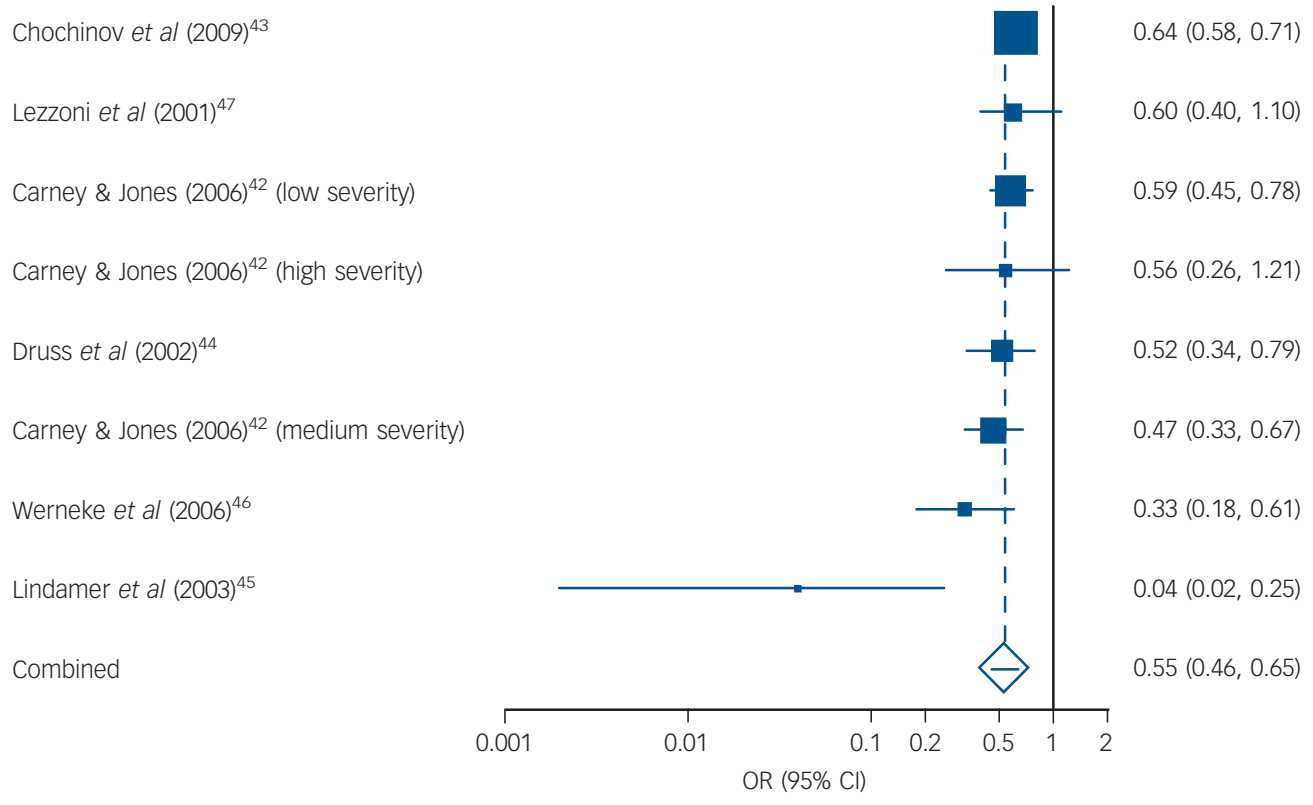

Fig. 4 Mammography screening in women with severe mental illness. Pooled odds ratios: random effects meta-analysis.

discomfort when attending for mammography, and education and reassurance might ameliorate these concerns and improve attendance. ${ }^{77}$ If the low receipt of screening is explained by low help-seeking rates then more attention is needed during the invitation process aimed at those with known psychiatric diagnoses and other low-attendance groups. A follow-up telephone call can improve attendance in those with mental illness. ${ }^{78}$ A second explanation might be the influence of cognitive impairment on decision-making. Most people with mental illness do not have substantial enduring cognitive impairment, but several past studies have found that low uptake occurs in those with learning disabilities. ${ }^{33,79}$ This requires further study.

Not all mammography occurs as a result of routine screening invitations. Indeed, in many low-income countries mammography is by clinician request. However, in such countries most clinicians do not send asymptomatic women for screening, unless the patient makes a specific request. ${ }^{80}$ Hence a number of authors have stipulated the importance of good communication between primary care providers and mental health services to maximise cancer screening among women with mental illness. ${ }^{77,81,82}$ Research in the general population has also stipulated the importance of having a primary care provider to improve screening rates, ${ }^{83}$ but it may be that trust and social support are additionally important to facilitate screening attendance in women with mental illness. ${ }^{11}$ The importance of good communication and continuity of care has previously been emphasised in a qualitative study involving people with SMI and healthcare professionals. ${ }^{84}$ However, the low screening rates may be partly ascribed to a failure of primary healthcare providers to take the physical healthcare complaints of people with mental illness seriously. ${ }^{4}$ For instance, healthcare providers may fail to screen people with mental illness for cancer owing to a preoccupation with other comorbidities and confusion around symptom attributes. ${ }^{11}$ One author stated that providers attributed many of the patients' physical complaints to their psychiatric symptoms, which resulted in an underestimation of the post-test probability of other medical conditions. ${ }^{54}$

\section{Study limitations}

It is important that a number of limitations are considered when considering the results of this review. First, most of the analyses that we conducted had considerable heterogeneity. We attempted to negate this and improve clinical relevance by stratifying the results according to clinical diagnosis and also by reporting only random effects meta-analysis. Second, most studies were conducted in North America, and may not be generalisable to other areas of the world with different healthcare systems. Third, it may be that shared risk factors such as social deprivation may account for the low mammography uptake, but it was not possible to investigate this clearly within the analysis. Fourth, the time frame over which mammograms were recorded varied across studies. Lastly, there was heterogeneity in the classification of mental illness, with a range of classification criteria used, and some authors used retrospective history. However, despite these factors, the results from our large meta-analysis were consistent: people with mental illness, particularly those with serious disorders, are substantially less likely to receive mammography screening compared with members of the general population.

\section{Clinical implications}

People with mental illness are at significant risk of not attending breast cancer screening although reasons for this disparity remain to be confirmed. Most research shows that people with mental illness receive inferior medical care. ${ }^{1,8}$ Cancer is particularly burdensome in people with mental illness, and clearly such people should receive care that is at least comparable with care given to the general population. Although there has been some debate in the general medical literature regarding the use of mammography (see, for example, Jorgensen \& Kotzsche), ${ }^{85}$ the inequality demonstrated within this review is clearly not proportionate to this group's healthcare needs. This is particularly so when research has demonstrated that among people with mental illness cancer is often detected later, and when it is detected more metastases are often found. ${ }^{27}$ However, care is needed when employing large-scale mammography screening because false positives may cause psychological harm. ${ }^{85} \mathrm{~A}$ recent longitudinal study found that in the general population annual mammography screening had no effect on breast cancer mortality beyond that of physical breast examinations. ${ }^{86}$ However, it remains unclear if this finding applies to those with mental illness. Indeed, people with 
severe mental illness may not receive regular physical health checks and are probably less likely to carry out self-examination. In order to enhance breast cancer screening, it is important that there is better communication between NHS England's screening services, primary care providers and mental health services. ${ }^{77,81,82}$ Efforts should also be made to educate and support women with mental illness to engage in breast cancer screening and social support may be particularly important in achieving this. ${ }^{11}$

\section{Future research}

Future prospective research should investigate the barriers to as well as the facilitators of mammography screening among women with mental illness. This should use both qualitative and quantitative research methods, drawing upon the experiences of the patients and of mental healthcare and primary care providers. Additionally, it is essential that prospective longitudinal studies are conducted to investigate the influence of mammography screening upon the diagnosis (including false positives), treatment and ultimately the mortality of women with mental illness.

Alex J. Mitchell, MD, Department of Psycho-oncology, Cancer and Molecular Medicine, University of Leicester; Isabel Espirito Santo Pereira, Motahare Yadegarfar, Shingai Pepereke, Vongai Mugadza, University of Leicester Medica School, Leicester; Brendon Stubbs, MSC, MCSP, Faculty of Education and Health, University of Greenwich, London, UK

Correspondence: Dr Alex J. Mitchell, Department of Psycho-oncology, Cance and Molecular Medicine, University of Leicester, Leicester LE1 5WW, UK. Email: ajm80@le.ac.uk

First received 27 Feb 2014, final revision 16 Jun 2014, accepted 30 Jul 2014

\section{Acknowledgements}

We thank Ms Verity Markham for additional help with an earlier draft of this paper.

\section{References}

1 Thornicroft G. Physical health disparities and mental illness: the scandal of premature mortality. Br J Psychiatry 2011; 199: 441-2.

2 De Hert M, Correll CU, Bobes J, Cetkovich-Bakmas M, Cohen D, Asai I, et al. Physical illness in patients with severe mental disorders. I. Prevalence, impact of medications and disparities in health care. World Psychiatry 2011; 10: $52-77$

3 De Hert M, Cohen D, Bobes J, Cetkovich-Bakmas M, Leucht S, Ndetei DM, et al. Physical illness in patients with severe mental disorders. II. Barriers to care, monitoring and treatment guidelines, plus recommendations at the system and individual level. World Psychiatry 2011; 10: 138-51.

4 Rethink Mental Illness. Lethal Discrimination (http://www.rethink.org/media/ 810988/Rethink\%20Mental\%20Illness\%20-\%20Lethal\%20Discrimination.pdf).

5 Lawrence D, Hancock KJ, Kisely S. The gap in life expectancy from preventable physical illness in psychiatric patients in Western Australia: retrospective analysis of population based registers. BMJ 2013; 346: f2539.

6 Nielsen RE, Uggerby AS, Jensen SOW, McGrath JJ. Increasing mortality gap for patients diagnosed with schizophrenia over the last three decades a Danish nationwide study from 1980 to 2010. Schizophr Res 2013; 146 : 22-7.

7 Stubbs B, De Hert M, Sepehry AA, Correll C, Mitchell A, Soundy A, et al. A meta-analysis of prevalence estimates and moderators of low bone mass in people with schizophrenia. Acta Psychiatr Scand 2014 (doi: 10.1111/acps.12313)

8 Mitchell AJ, Malone D, Doebbeling CC. Quality of medical care for people with and without comorbid mental illness and substance misuse: systematic review of comparative studies. Br J Psychiatry 2009; 194: 491-9.

9 Lord O, Malone D, Mitchell AJ. Receipt of preventive medical care and medical screening for patients with mental illness: a comparative analysis. Gen Hosp Psychiatry 2010; 32: 519-43.

10 Mitchell AJ, Lawrence D. Revascularisation and mortality rates following acute coronary syndromes in people with severe mental illness: comparative meta-analysis. Br J Psychiatry 2011; 198: 434-41.
11 Aggarwal A, Pandurangi A, Smith W. Disparities in breast and cervical cancer screening in women with mental illness: a systematic literature review. Am J Prevent Med 2013; 44: 392-8.

12 O'Rourke RW, Diggs BS, Spight DH, Robinson J, Elder KA, Andrus J, et al. Psychiatric illness delays diagnosis of esophageal cancer. Dis Esophagus 2008; 21: 416-21.

13 Baillargeon J, Kuo YF, Lin YL, Raji MA, Singh A, Goodwin JS. Effect of mental disorders on diagnosis, treatment, and survival of older adults with colon cancer. J Am Geriatr Soc 2011; 59: 1268-73.

14 World Health Organization. Cancer Control: Early Detection. Knowledge Into Action. WHO Guide for Effective Programmes. WHO, 2007 (http:// www.who.int/cancer/modules/en/index.html).

15 Centers for Disease Control and Prevention. Vital signs: breast cancer screening among women aged 50-74 years -United States, 2008. MMWR Morb Mortal Wkly Rep 2010; 59; 813-6.

16 Smith RA. International programs for the detection of breast cancer. Salud Publica Mex 2011; 53: 394-404.

17 US Preventive Services Task Force. Screening for breast cancer: U.S. Preventive Services Task Force recommendation statement. Ann Intern Med 2009; 151: 716-26.

18 Duffy SW, Tabar L, Olsen AH, Vitak B, Allgood PC, Chen THH, et al. Absolute numbers of lives saved and overdiagnosis in breast cancer screening, from a randomized trial and from the Breast Screening Programme in England. $J$ Med Screen 2010; 17: 25-30.

19 Marmot MG, Altman DG, Cameron DA, Dewar JA, Thompson SG, Wilcox M. The benefits and harms of breast cancer screening: an independent review. Br J Cancer 2013; 108: 2205-40.

20 Cancer Research UK. Breast Cancer Screening Benefits and Harms (http:// www.cancerresearchuk.org/cancer-info/cancerstats/types/breast/screening/ Benefits-and-Harms).

21 Hendrick RE, Smith RA, Rutledge $\mathrm{JH}$, Smart CR. Benefit of screening mammography in women aged 40-49: a new meta-analysis of randomized controlled trials. J Natl Cancer Inst Monogr 1997; 87-92.

22 Kerlikowske K, Grady D, Ernster V. Benefit of mammography screening in women ages 40-49 years: current evidence from randomized controlled trials. Cancer 1995; 76: 1679-81.

23 Magnus MC, Ping M, Shen MM, Bourgeois J, Magnus JH. Effectiveness of mammography screening in reducing breast cancer mortality in women aged 39-49 years: a meta-analysis. J Womens Health (Larchmt) 2011; 20: 845-52.

24 Gotzsche PC, Jorgensen KJ. Screening for breast cancer with mammography. Cochrane Database Syst Rev 2013; 6: CD001877.

25 Osborn DPJ, Levy G, Nazareth I, Petersen I, Islam A, King MB. Relative risk of cardiovascular and cancer mortality in people with severe mental illness from the United Kingdom's General Practice Research Database. Arch Gen Psychiatry 2007; 64: 242-49.

26 Musuuza JS, Sherman ME, Knudsen KJ, Sweeney HA, Tyler CV, Koroukian SM. Analyzing excess mortality from cancer among individuals with mental illness. Cancer 2013; 119: 2469-76.

27 Kisely S, Crowe E, Lawrence D. Cancer-related mortality in people with mental illness. JAMA Psychiatry 2013; 70: 209-17.

28 Ji J, Sundquist K, Ning Y, Kendler KS, Sundquist J, Chen X. Incidence of cancer in patients with schizophrenia and their first-degree relatives: a population-based study in Sweden. Schizophr Bull 2013; 39: 527-36.

29 Stroup DF, Berlin JA, Morton SC, Olkin I, Williamson GD, Rennie D, et al Meta-analysis of observational studies in epidemiology: a proposal for reporting. Meta-analysis Of Observational Studies in Epidemiology (MOOSE) group. JAMA 2000; 283: 2008-12.

30 Moher D, Liberati A, Tetzlaff J, Altman DG, PRISMA Group. Preferred reporting items for systematic reviews and meta-analyses: the PRISMA statement. PLOS Med 2009; 6: 1-6.

31 American Psychiatric Association. Diagnostic and Statistical Manual of Mental Disorders (4th edn, revised) (DSM-IV-TR). APA, 2000

32 World Health Organization. The ICD-10 Classification of Mental and Behavioural Disorders - Diagnostic Criteria for Research. WHO, 1993.

33 Sullivan SG, Glasson EJ, Hussain R, Petterson BA, Slack-Smith LM, Montgomery PD, et al. Breast cancer and the uptake of mammography screening services by women with intellectual disabilities. Prevent Med 2003; 37: $507-12$

34 Wells G, Shea B, O'Connell D, Peterson JEA. The Newcastle-Ottawa Scale (NOS) for assessing the quality of nonrandomised studies in meta-analyses (http://www.ohri.ca/programs/clinical_epidemiology/oxford.asp).

35 Zhang J, Yu KF. What's the relative risk? A method of correcting the odds ratio in cohort studies of common outcomes. JAMA 1998; 280: 1690-1.

36 Higgins JPT, Thompson SG, Deeks JJ, Altman DG. Measuring inconsistency in meta-analyses. BMJ 2003; 327: 557-60. 
37 DerSimonian R, Laird N. Meta-analysis in clinical trials. Control Clin Trials 1986; 7: 177-88.

38 Egger M, Davey Smith G, Schneider M, Minder C. Bias in meta-analysis detected by a simple, graphical test. BMJ 1997; 315: 629-34.

39 Begg CB, Mazumdar M. Operating characteristics of a rank correlation test for publication bias. Biometrics 1994; 50: 1088-101.

40 Baumeister $\mathrm{H}$, Harter M. Prevalence of mental disorders based on general population surveys. Soc Psychiatry Psychiatr Epidemiol 2007; 42: 537-46.

41 Wittchen $\mathrm{HU}$, Jacobi F. Size and burden of mental disorders in Europe - a critical review and appraisal of 27 studies. Eur Neuropsychopharmacol 2005; 15: 357-76.

42 Carney CP, Jones LE. The influence of type and severity of mental illness on receipt of screening mammography. J Gen Intern Med 2006; 21: 1097-104.

43 Chochinov HM, Martens PJ, Prior HJ, Fransoo R, Burland E. Does a diagnosis of schizophrenia reduce rates of mammography screening? A Manitoba population-based study. Schizophr Res 2009; 113: 95-100.

44 Druss BG, Rosenheck RA, Desai MM, Perlin JB. Quality of preventive medical care for patients with mental disorders. Med Care 2002; 40: 129-36.

45 Lindamer LA, Buse DC, Auslander L, Unutzer J, Bartels SJ, Jeste DV. A comparison of gynecological variables and service use among older women with and without schizophrenia. Psychiatr Serv 2003; 54: 902-4.

46 Werneke U, Horn O, Maryon-Davis A, Wessely S, Donnan S, McPherson K. Uptake of screening for breast cancer in patients with mental health problems. J Epidemiol Commun Health 2006; 60: 600-5.

47 lezzoni LI, McCarthy EP, Davis RB, Harris-David L, O'Day B. Use of screening and preventive services among women with disabilities. Am J Med Qual 2001; 16: 135-44.

48 Druss BG, Rask K, Katon WJ. Major depression, depression treatment and quality of primary medical care. Gen Hosp Psychiatry 2008; 30: 20-5.

49 Green CA, Pope CR. Depressive symptoms, health promotion, and health risk behaviors. Am J Health Promot 2000; 15: 29-34.

50 Patten SB, Williams JVA, Lavorato $\mathrm{DH}$, Eliasziw M. The effect of major depression on participation in preventive health care activities. BMC Public Health 2009; 9: 87.

51 Peytremann-Bridevaux I, Voellinger R, Santos-Eggimann B. Healthcare and preventive services utilization of elderly Europeans with depressive symptoms. J Affect Disord 2008; 105: 247-52.

52 Pirraglia PA, Sanyal P, Singer DE, Ferris TG. Depressive symptom burden as a barrier to screening for breast and cervical cancers. $J$ Womens Health (Larchmt) 2004; 13: 731-8.

53 Stecker T, Fortney JC, Prajapati S. How depression influences the receipt of primary care services among women: a propensity score analysis. $J$ Womens Health (LarChmt) 2007; 16: 198-205.

54 Masterson EA, Hopenhayn C, Christian WJ. Self-reported mental health status and recent mammography screening. J Womens Health (Larchmt) 2010; 19 1569-76.

55 Ludman EJ, Ichikawa LE, Simon GE, Rohde P, Arterburn D, Operskalski BH, et al. Breast and cervical cancer screening: specific effects of depression and obesity. Am J Prevent Med 2010; 38: 303-10.

56 Vigod S, Kurdyak P, Stewart D, Gnam W, Goering P. Depressive symptoms as a determinant of breast and cervical cancer screening in women: a population-based study in Ontario, Canada. Arch Womens Ment Health 2011; 14: 159-68.

57 Aggarwal A, Freund K, Sato A, Adams-Campbell LL, Lopez AM, Lessin LS, et al. Are depressive symptoms associated with cancer screening and cance stage at diagnosis among postmenopausal women? The Women's Health Initiative observational cohort. J Womens Health (Larchmt) 2008; 17: 1353-61.

58 Blackwell DL, Martinez ME, Gentleman JF. Women's compliance with public health guidelines for mammograms and Pap tests in Canada and the United States: an analysis of data from the Joint Canada/United States Survey of Health. Womens Health Issues 2008; 18: 85-99.

59 Kempe KL, Larson RS, Shetterley S, Wilkinson A. Breast cancer screening in an insured population: whom are we missing? Perm J 2013; 17: 38-44.

60 Schwartz MD, Taylor KL, Willard KS. Prospective association between distress and mammography utilization among women with a family history of breast cancer. J Behav Med 2003; 26: 105

61 Thorpe JM, Kalinowski CT, Patterson ME, Sleath BL. Psychological distress as a barrier to preventive care in community-dwelling elderly in the United States. Med Care 2006; 44: 187-91.

62 Leiferman JA, Pheley AM. The effect of mental distress on women's preventive health behaviors. Am J Health Promot 2006; 20: 196-9.
63 Lasser $K E$, Zeytinoglu $H$, Miller E, Becker AE, Hermann RC, Bor DH. Do women who screen positive for mental disorders in primary care have lower mammography rates? Gen Hosp Psychiatry 2003; 25: 214-6.

64 Yee EFT, White R, Lee SJ, Washington DL, Yano EM, Murata G, et al. Mental illness: is there an association with cancer screening among women veterans? Womens Health Issues 2011; 21: S195-202.

65 Koroukian SM, Bakaki PM, Golchin N, Tyler C, Loue S. Mental illness and use of screening mammography among Medicaid beneficiaries. Am J Prevent Med 2012; 42: 606-9.

66 Health and Social Care Information Centre. Breast Cancer Screening Program in England. HSCIC, 2013 (http://www.hscic.gov.uk/catalogue/PUB10339).

67 Perini G, Grigoletti L, Hanife B, Biggeri A, Tansella M, Amaddeo F. Cancer mortality among psychiatric patients treated in a community-based system of care: a 25-year case register study. Soc Psychiatry Psychiatr Epidemiol 2014; 49: 693-701.

68 Osborn DP, Baio G, Walters K, Petersen I, Limburg H, Raine R, et al. Inequalities in the provision of cardiovascular screening to people with severe mental illnesses in primary care: cohort study in the United Kingdom THIN Primary Care Database 2000-2007. Schizophr Res 2011; 129: 104-10.

69 Roberts L, Roalfe A, Wilson S, Lester H. Physical health care of patients with schizophrenia in primary care: a comparative study. Family Pract 2007; 24 34-40.

70 Mitchell AJ, Hardy SA. Screening for metabolic risk among patients with severe mental illness and diabetes: a national comparison. Psychiatr Serv 2013; 64: 1060-3.

71 Mitchell AJ, Lord O, Malone D. Differences in the prescribing of medication for physical disorders in individuals with $\mathrm{v}$. without mental illness: metaanalysis. Br J Psychiatry 2012; 201: 435-43.

72 Ng DM, Jeffery RW. Relationships between perceived stress and health behaviors in a sample of working adults. Health Psychol 2003; 22: 638-42.

73 O'Donnell S, Goldstein B, DiMatteo MR, Fox SA, John CR, Obrzut JE. Adherence to mammography and colorectal cancer screening in women $50-80$ years of age: the role of psychological distress. Womens Health IsS 2010; 20: 343-9.

74 Kotwal AA, Schumm P, Mohile SG, Dale W. The influence of stress, depression, and anxiety on PSA screening rates in a nationally representative sample. Med Care 2012; 50: 1037-44.

75 Consedine NS, Morgenstern AH, Kudadjie-Gyamfi E, Magai C, Neugut Al. Prostate cancer screening behavior in men from seven ethnic groups: the fear factor. Cancer Epidemiol Biomarkers Prev 2006; 15: 228-37.

76 Hardy S, Gray R. Is the use of an invitation letter effective in prompting patients with severe mental illness to attend a primary care physical health check? Prim Health Care Res Dev 2012; 13: 347-52.

77 Kahn LS, Fox CH, Krause-Kelly J, Berdine DE, Cadzow RB. Identifying barriers and facilitating factors to improve screening mammography rates in women diagnosed with mental illness and substance use disorders. Women Health 2005; 42: 111-26.

78 Mitchell AJ, Selmes T. Why don't patients attend their appointments? Maintaining engagement with psychiatric services. Adv Psychiatr Treatment 2007; 13: 423-34.

79 Legg JS, Clement DG, White KR. Are women with self-reported cognitive limitation at risk for underutilization of mammography? I Health Care Poor Underserved. 2004; 15: 688-702.

80 Temitope B, Daniel A, Ademola A. A survey of physicians' attitudes and practices to screening mammography in Osogbo \& Ibadan, South-West Nigeria. Internet Journal of Radiology 2006; 6: 1.

81 Miller E, Lasser KE, Becker AE. Breast and cervical cancer screening for women with mental illness: patient and provider perspectives on improving linkages between primary care and mental health. Arch Womens Ment Health 2007; 10: 189-97.

82 Friedman LC, Puryear LJ, Moore A, Green CE. Breast and colorectal cancer screening among low-income women with psychiatric disorders. Psychooncology 2005; 14: 786-91.

83 Starfield B, Leiyu S, Macinko J. Contribution of primary care to health systems and health. Milbank Q 2005; 83: 457-502.

84 Lester HE, Soroham H, Tritter JQ. Patients' and health professionals' views on primary care for people with serious mental illness: focus group study. BMJ 2005; 330: 1122-6.

85 Jorgensen KJ, Gotzsche PC. Overdiagnosis in publicly organised mammography screening programmes: systematic review of incidence trends. BMJ 2009; 339: b2587.

86 Miller AB, Wall C, Baines CJ, Sun P, To T, Narod SA. Twenty five year followup for breast cancer incidence and mortality of the Canadian National Breast Screening Study: randomised screening trial. BMJ 2014; 348: g366. 